\title{
Photocuring Behaviors of UV-Curable Perfluoropolyether-Based Fluoropolymers with and without Tertiary Amine
}

\author{
Jung-Dae Cho ${ }^{1}$, Dong-Pyo Kim², Jin-Who Hong ${ }^{3 *}$ \\ ${ }^{1}$ Institute of Photonics \& Surface Treatment, Q-Sys Co. Ltd., 971-14 Wolchul-Dong, Buk-Gu, Gwangju, South Korea \\ ${ }^{2}$ Department of Chemical Engineering, Pohang University of Science \& Technology, Pohang, South Korea \\ ${ }^{3}$ Department of Polymer Science \& Engineering, Chosun University, Gwangju, South Korea \\ Email: *jhhong@chosun.ac.kr
}

Received September 26, 2013; revised October 26, 2013; accepted November 3, 2013

Copyright (c) 2014 Jung-Dae Cho et al. This is an open access article distributed under the Creative Commons Attribution License, which permits unrestricted use, distribution, and reproduction in any medium, provided the original work is properly cited. In accordance of the Creative Commons Attribution License all Copyrights (C) 2014 are reserved for SCIRP and the owner of the intellectual property Jung-Dae Cho et al. All Copyright (C) 2014 are guarded by law and by SCIRP as a guardian.

\section{ABSTRACT}

UV-curable perfluoropolyether (PFPE)-based fluoropolymer (PFPE-DMA) was synthesized and the photocuring behaviors of PFPE-DMA/HDDA systems with and without tertiary triethyl amine (TEA) were investigated using photo-DSC under air and nitrogen atmospheres. Photo-DSC analysis revealed that $\mathbf{N}_{2}$ purging and the presence of TEA mitigated oxygen inhibition in the photopolymerization of the UV-curable free-radical PFPE-DMA/ HDDA system. In addition, TEA synergistically acted as a coinitiator or photosynergist under nitrogen atmosphere, which increased the cure rate and percentage conversion for the photopolymerization of PFPE-DMA/ HDDA. TEA acted as both oxygen scavenger and photosynergist. The results presented here demonstrate that investigating the photocuring behaviors of PFPE-DMA/HDDA systems is very helpful to determine the optimal curing conditions for the PFPE-DMA fluoropolymer.

\section{KEYWORDS}

\section{Fluoropolymer; Photocuring Behaviors; Oxygen Inhibition; Photosynergist}

\section{Introduction}

Photocurable fluorinated monomers and oligomers have recently received widespread attention due to their desirable characteristics resulting from the presence of fluorine atoms, such as releasing properties, low refractive index, water impermeability, chemical stability, and weathering resistance. Various fluorinated materials have already been used in electronics-industry applications such as photolithographic fabrication, UV nanoimprinting lithography, and the production of microelectromechanical system (MEMS) devices [1-6].

The synthesis and curing properties of UV-curable fluoropolymers containing perfluoropolyether (PFPE) structures have been reported [7-9]. The UV-cured PFPE-based fluoropolymers exhibit low surface energy, low mo-

"Corresponding author. dulus, low toxicity, and high gas permeability. They can also be used to produce transparent films with very high hydrophobicity after UV curing, and show remarkable resistance to organic solvents using in microfluidic-device applications. These properties have the potential to expand the field of microfluidics to many novel applications.

The present paper describes observations of the photocuring behaviors of a PFPE-based fluoropolymer. Aaccurate kinetics analyses yield quantitative data on the photocuring behaviors of PFPE-based systems for designing new types of MEMS devices [10-12].

We synthesized a UV-curable PFPE-based fluoropolymer (PFPE-DMA) and investigated the curing behaviors of free-radical photopolymerizations of PFPE-DMA/ HDDA systems with and without tertiary amine under air and nitrogen atmospheres using photodifferential scan- 
ning calorimetry (photo-DSC).

\section{Experimental}

\subsection{Materials Synthesis}

PFPE-based fluoropolymer (PFPE-DMA) was synthesized based on the work of Priola et al. [7-9]. The reaction involved the methacrylate functionalization of a commercially available PFPE diol $\left(\mathrm{M}_{\mathrm{n}}=4000 \mathrm{~g} / \mathrm{mol}\right.$, Solvay Solexis) with 2-isocyanatoethyl methacrylate (Hesita Laboratories). 1,6-Hexanediol diacrylate (HDDA, UCB Chemicals) was used as a diluent monomer, 2,4,6-trimethylbenzoyl-diphenyl-phosphineoxide (TPO, CibaGeigy) was used as a free-radical photoinitiator, and triethyl amine (TEA, Aldrich) was used as a synergist. All the materials were used as received. The liquid formulations were prepared by directly mixing TPO with PFPE-DMA and HDDA at $30^{\circ} \mathrm{C}$ for about $1 \mathrm{~h}$ under vigorous stirring. The processes of the synthesis and UV curing of PFPEDMA are shown in Figure 1.

\subsection{Photodifferential Scanning Calorimetry}

Photo-DSC experiments were performed using a differential scanning calorimeter equipped with a photocalorimetric accessory (TA 5000/DPC System). The initiation light source was a 200-W high-pressure mercury lamp that gave a UV light intensity at the sample of 14 $\mathrm{mW} / \mathrm{cm}^{2}$ at $365 \mathrm{~nm}$. Samples weighing $1.0 \pm 0.1$ (mean \pm SD) $\mathrm{mg}$ were placed in uncovered aluminum pans, and a reference aluminum pan was left empty. The exothermic heat for photocuring at $100^{\circ} \mathrm{C}$ under a nitrogen atmosphere was $95 \mathrm{~J} / \mathrm{g}$, and was considered as the total heat, $\Delta H_{\text {total }}$, for the fully cured PFPE-DMA/HDDA polymer network. This value was used in the subsequent analysis. TA Instruments software was employed to obtain the results from the photo-DSC experiments.

\section{Results and Discussion}

UV-initiated photopolymerization based on acrylates and

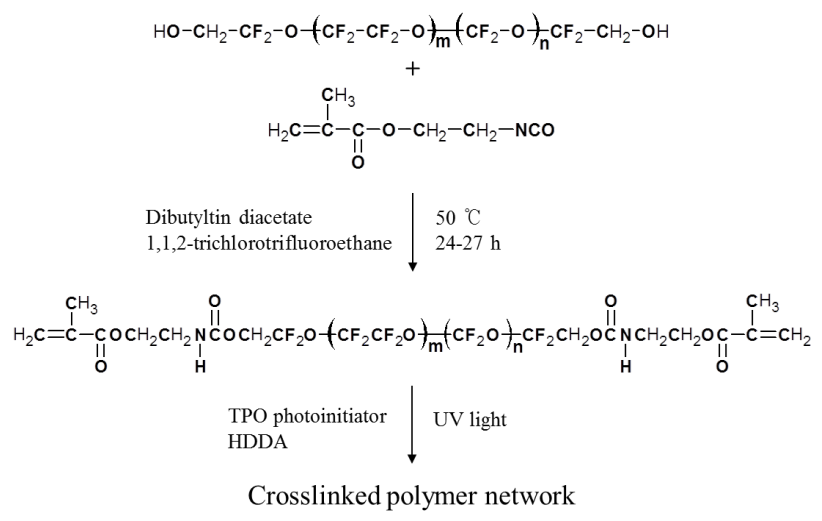

Figure 1. Synthesis and UV curing of PFPE-DMA. methacrylates has received considerable attention due to the associated fast and solvent-free curing, multifunctionality, and negligible toxicity [13-18]. However, they are vulnerable to the inhibition of free-radical polymerization by oxygen. Two mechanisms proposed for this inhibition in a UV-curable free-radical system are (1) quenching of the excited states of the photoinitiator and (2) scavenging of free radicals. Purging with nitrogen and adding amines to the UV-curable free-radical system are known to mitigate oxygen inhibition [13], and hence we used these methods to obtain the optimum cure rate and cure conversion of the PFPE-DMA/HDDA system.

We used photo-DSC to elucidate the effects of $\mathrm{N}_{2}$ purging and tertiary triethyl amine (TEA) on the photocuring behaviors of the four UV-curable PFPE-DMA/ HDDA formulations listed in Table 1. This technique is capable of providing photopolymerization kinetics data in which the measured heat flow can be converted directly to the ultimate percentage conversion and polymerization rate for a given formulation, with the data obtained reflecting the overall curing reaction of the sample. However, it should be noted that the cure kinetics data obtained in this study are essentially empirical and do not provide any mechanistic insight [10-12].

The photo-DSC exotherms for the photopolymerization of the UV-curable PFPE-DMA/HDDA systems with and without triethyl amine under air and nitrogen atmosphere are illustrated in Figure 2. Figure 3 plots the percentage conversion versus irradiation time derived from Figure 2 for the photopolymerization of the above systems. The amounts of heat released, the maxima, the ultimate percentage conversions, and the maximum polymerization rates $\left(R_{\mathrm{p}, \max }\right)$ derived from Figures 2 and 3 are collected in Table 2.

The presence of $\mathrm{N}_{2}$ markedly increased the cross-link density (which is related to the exotherm and percentage conversion) and the cure rate (which is related to the maximum and $\left.R_{\mathrm{p}, \max }\right)$. This is ascribed to the absence of inhibition by oxygen, which not only increases the rate of generation of free radicals by the photoinitiation process, but also enhances the overall rate and degree of cure.

Table 1. Formulations of UV-curable PFPE-DMA/HDDA systems with and without triethyl amine under air and nitrogen atmospheres. Data values are weight percentages.

\begin{tabular}{ccccc}
\hline \multirow{2}{*}{ Component } & \multicolumn{2}{c}{ Air } & \multicolumn{2}{c}{ Nitrogen } \\
\cline { 2 - 5 } & A & B & C & D \\
\hline $\begin{array}{c}\text { PFPE-DMA } \\
\text { (fluoropolymer) }\end{array}$ & 90 & 90 & 90 & 90 \\
$\begin{array}{c}\text { HDDA }^{\mathrm{a}} \\
\text { (diluent) }\end{array}$ & 10 & 10 & 10 & 10 \\
$\begin{array}{c}\text { TPO }^{\mathrm{b}} \\
(\text { photoinitiator) }\end{array}$ & 3 & 3 & 3 & 3 \\
$\begin{array}{c}\text { TEA }^{\mathrm{c}} \\
\text { (amine synergist) }\end{array}$ & - & 3 & - & 3 \\
\hline
\end{tabular}

${ }^{\mathrm{a}}$ UCB Chemicals; ${ }^{\mathrm{b}}$ Ciba-Geigy; ${ }^{\mathrm{c}}$ Aldrich. 


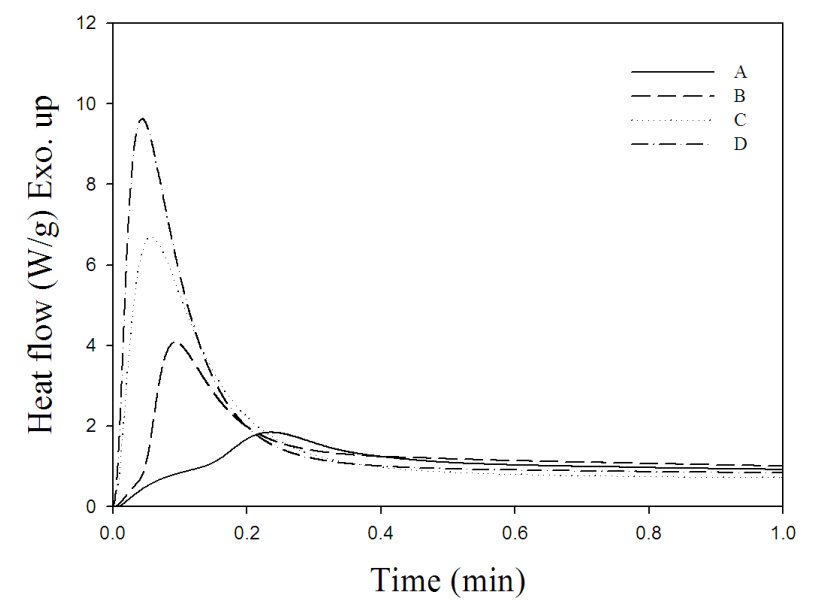

Figure 2. Photo-DSC exotherms for the photopolymerization of formulations A-D listed in Table 1. Isothermal curing temperature: $30^{\circ} \mathrm{C}$; sample weight: $1.0 \mathrm{mg}$; light intensity: $14 \mathrm{~mW} / \mathrm{cm}^{2}$ at $365 \mathrm{~nm}$.

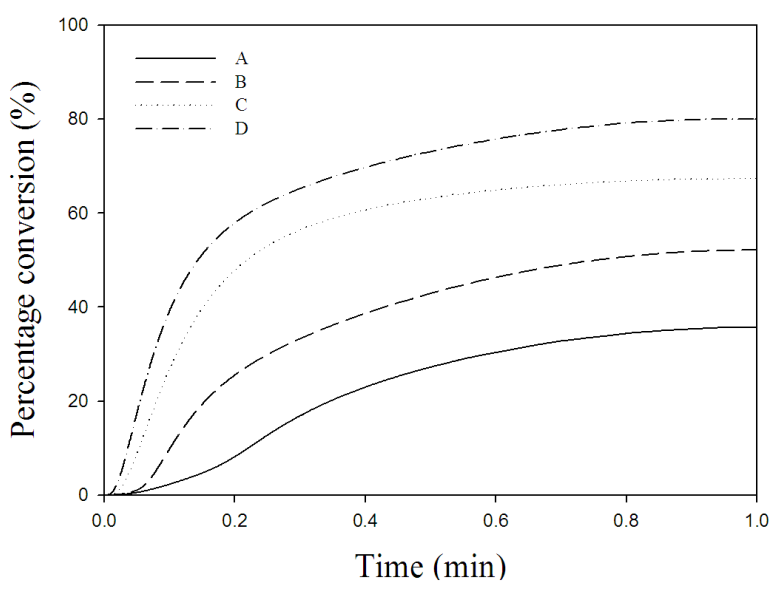

Figure 3. Percentage conversion profiles for the photopolymerization of formulations A-D under the conditions described in the legend of Figure 2.

Table 2. Exotherm data for the photopolymerization of formulations A-D.

\begin{tabular}{ccccc}
\hline Formulation & $\begin{array}{c}\Delta H \\
(\mathrm{~J} / \mathrm{g})\end{array}$ & $\begin{array}{c}\text { Maximum } \\
(\mathrm{min})\end{array}$ & $\begin{array}{c}\text { Conversion } \\
(\%)\end{array}$ & $\begin{array}{c}R_{\mathrm{p}, \max } \\
\left(\mathrm{min}^{-1}\right)\end{array}$ \\
\hline $\mathrm{A}$ & 38 & 0.233 & 36 & 0.93 \\
$\mathrm{~B}$ & 55 & 0.093 & 52 & 2.26 \\
$\mathrm{C}$ & 71 & 0.057 & 68 & 3.71 \\
$\mathrm{D}$ & 84 & 0.043 & 80 & 5.38 \\
\hline
\end{tabular}

${ }^{\mathrm{a}} R_{\mathrm{p}, \max }$ : maximum polymerization rate $\left(R_{\mathrm{p}}=\mathrm{d} \alpha / \mathrm{d} t\right.$, where $\alpha$ is the fraction of resin converted).

The addition of amine to the formulation significantly increased the cross-link density and the cure rate of the UV-curable PFPE-DMA/HDDA system under both air and nitrogen atmospheres. This is attributable to the tertiary triethyl amine reacting with oxygen and scavenging peroxy intermediates formed by the reaction of oxygen with radical sites, thereby reducing the retarding effect of oxygen on the cure rate and also helping to increase the efficiency of the photopolymerization process.

It is notable that the cross-link density and the cure rate were markedly higher for the formulation $\mathrm{D}$. This indicates that triethyl amine synergistically acts as a coinitiator or photosynergist in the absence of oxygen for the photopolymerization of the UV-curable free-radical system, which improves the efficiency of the photoinitiation process so as to produce more active species and accelerate the cure rate and percentage conversion of the UV-curable PFPE-DMA/HDDA system. Tertiary triethyl amine acts as both oxygen scavenger and photosynergist. A proposed reaction mechanism of oxygen scavenging and photosynergism by triethyl amine is given in Figure 4.

\section{Conclusions}

We have synthesized a UV-curable PFPE-based fluoropolymer (PFPE-DMA) and studied the photocuring behaviors of PFPE-DMA/HDDA systems with and without tertiary triethyl amine (TEA) under air and nitrogen atmospheres using photo-DSC.

Photo-DSC analysis revealed that $\mathrm{N}_{2}$ purging and the presence of TEA mitigated oxygen inhibition in the photopolymerization of the UV-curable free-radical PFPEDMA/HDDA system. In addition, TEA synergistically acted as a coinitiator or photosynergist under a nitrogen atmosphere, which increased the cure rate and percentage conversion for the photopolymerization of PFPE-DMA/ HDDA. TEA acted as both oxygen scavenger and photosynergist. The results presented here demonstrate that investigating the photocuring behaviors of PFPE-DMA/ HDDA system is very helpful to determine the optimal curing conditions for the PFPE-DMA fluoropolymer and

$$
\begin{aligned}
& \text { Photoinitiation } \\
& \mathrm{Pl} \longrightarrow \mathrm{Pl}^{*} \\
& \mathrm{PI}^{*}+\left(\mathrm{C}_{2} \mathrm{H}_{5}\right)_{3} \mathrm{~N} \longrightarrow\left[\mathrm{PI} \ldots\left(\mathrm{C}_{2} \mathrm{H}_{5}\right)_{3} \mathrm{~N}\right]^{*} \\
& \text { Exciplex } \stackrel{\text { H-Transfer }}{\longrightarrow} \mathrm{PIH} \cdot+\left(\mathrm{C}_{2} \mathrm{H}_{5}\right)_{2} \mathrm{~N}^{2} \dot{\mathrm{C}} \mathrm{HCH}{ }_{3} \\
& \text { Oxygen scavenging } \\
& \left(\mathrm{C}_{2} \mathrm{H}_{5}\right)_{2} \mathrm{~N} \dot{\mathrm{C}} \mathrm{HCH}_{3}+\mathrm{O}_{2} \longrightarrow\left(\mathrm{C}_{2} \mathrm{H}_{5}\right)_{2} \mathrm{NCHCH}_{3} \\
& \mathrm{O}-\mathrm{OH}
\end{aligned}
$$

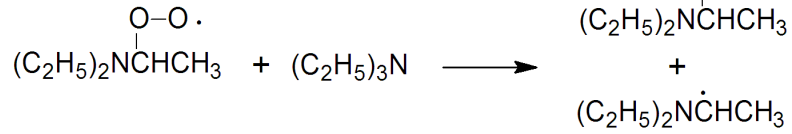

Photosynergism

$\left(\mathrm{C}_{2} \mathrm{H}_{5}\right)_{2} \mathrm{NCHCH}_{3}+$ PFPE DMA $\longrightarrow$ Propagation

Figure 4. Proposed reaction mechanisms of oxygen scavenging and photosynergism by tertiary amine. 
also will provide an insight for designing new MEMS devices using this material.

\section{REFERENCES}

[1] J. Scheirs, Modern Fluoropolymers,” Wiley, New York, 1997, pp. 435-485.

[2] M. Yamabe, “A Challenge to Novel Fluoropolymers,” Makromolekulare Chemie. Macromolecular Symposia, Vol. 64, No. 1, 1992, pp. 11-18. http://dx.doi.org/10.1002/masy.19920640104

[3] S. Turri, A. Sanguineti and R. Lecchi, "Novel Glass Fiber-Reinforced Composites Having a UV and Peroxy $\mathrm{Cu}-$ rable Fluoropolymer Matrix,” Macromolecular Materials and Engineering, Vol. 288, No. 9, 2003, pp. 708-716. http://dx.doi.org/10.1002/mame.200300021

[4] H. Lorenz, M. Despont, N. Fahrni, J. Brugger, P. Vettiger and P. Renaud, "High-Aspect-Ratio, Ultrathick, NegativeTone Near-UV Photoresist and Its Applications for MEMS," Sensors and Actuators A: Physical, Vol. 64, No. 1, 1998, pp. 33-39.

http://dx.doi.org/10.1016/S0924-4247(98)80055-1

[5] J. A. Rogers and H. H. Lee, "Unconventional Nanopatterning Techniques and Applications,” Wiley, New York, 2008. http://dx.doi.org/10.1002/9780470405789

[6] J. Taniguchi, H. Ito, J. Mizuno and T. Saito, "Nanoimprint Technology: Nanotransfer for Thermoplastic and Photocurable Polymers,” Wiley, New York, 2013. http://dx.doi.org/10.1002/9781118535059

[7] R. Bongiovanni, N. Pollicino, G. Gozzelino, G. Malucelli, A. Priola and B. Ameduri, "Surface Properties of Networks Containing Fluorinated Acrylic Monomers,” Polymers for Advanced Technologies, Vol. 7, No. 5-6, 1996, pp. 403-408.

http://dx.doi.org/10.1002/(SICI)1099-1581(199605)7:5/6 $<403::$ AID-PAT502>3.0.CO;2-0

[8] A. Priola, R. Bongiovanni, G. Malucelli, A. Pollicino, C. Tonelli and G. Simeone, "UV-curable Systems Containing Perfluoropolyether Structures: Synthesis and Characterisation," Macromolecular Chemistry and Physics, Vol. 198, No. 6, 1997, pp. 1893-1907.

http://dx.doi.org/10.1002/macp.1997.021980618

[9] B. Ameduri, R. Bongiovanni, G. Malucelli, A. Pollicino and A. Priola, "New Fluorinated Acrylic Monomers for the Surface Modification of UV-Curable Systems," Journal of Polymer Science Part A: Polymer Chemistry, Vol. 37, No. 1, 1999, pp. 77-87.
http://dx.doi.org/10.1002/(SICI)1099-0518(19990101)37: 1<77::AID-POLA9>3.0.CO;2-0

[10] F. Y. C. Boey and W. Qiang, "Experimental Modeling of the Cure Kinetics of an Epoxy-Hexaanhydro-4-Methylphthalicanhydride (MHHPA) System,” Polymer, Vol. 41, No. 6, 2000, pp. 2081-2094.

http://dx.doi.org/10.1016/S0032-3861(99)00409-7

[11] J. D. Cho, H. T. Ju and J. W. Hong, "Photocuring Kinetics of UV-Initiated Free-Radical Photopolymerizations with and without Silica Nanoparticles," Journal of Polymer Science Part A: Polymer Chemistry, Vol. 43, No. 3, 2005, pp. 658-670. http://dx.doi.org/10.1002/pola.20529

[12] J. D. Cho, H. T. Ju, Y. S. Park and J. W. Hong, "Kinetics of Cationic Photopolymerizations of UV-Curable EpoxyBased SU8-Negative Photoresists with and without Silica Nanoparticles," Macromolecular Materials and Engineering, Vol. 291, No. 9, 2006, pp. 1155-1163. http://dx.doi.org/10.1002/mame.200600124

[13] P. K. T. Oldring, "Chemistry \& Technology of UV \& EB Formulation for Coatings, Inks \& Paints,” SITA Technology, London, 1991.

[14] C. Decker, T. N. T. Viet, D. Decker and E. Weber-Koehl, "UV-Radiation Curing of Acrylate/Epoxide Systems," Polymer, Vol. 42, No. 13, 2001, pp. 5531-5541. http://dx.doi.org/10.1016/S0032-3861(01)00065-9

[15] S. C. Clark, C. E. Hoyle, S. Jönsson, F. Morel and C. Decker, "Photopolymerization of Acrylates Using N-aliphaticmaleimides as Photoinitiators,” Polymer, Vol. 40, No. 18, 1999, pp. 5063-5072. http://dx.doi.org/10.1016/S0032-3861(98)00734-4

[16] B. K. Kim, Y. H. Cho and J. S. Lee, "Effect of Polymer Structure on the Morphology and Electro-Optic Properties of UV Curable PNLCs,” Polymer, Vol. 41, No. 4, 2000, pp. 1325-1335. http://dx.doi.org/10.1016/S0032-3861(99)00282-7

[17] J. D. Cho, S. T. Han and J. W. Hong, “A Novel in Situ Relative-Conductivity-Based Technique for Monitoring the Cure Process of UV-Curable Polymers,” Polymer Testing, Vol. 26, No. 1, 2007, pp. 71-76. http://dx.doi.org/10.1016/j.polymertesting.2006.08.008

[18] O. Yaroshchuk, F. Elouali and U. Maschke, "Control of Phase Separation and Morphology of Thiol-Ene Based PDLCs by Curing Light Intensity,” Optical Materials, Vol. 32, No. 9, 2010, pp. 982-989.

http://dx.doi.org/10.1016/j.optmat.2010.02.017 